\title{
Biology of Diesel Exhaust Effects on Allergic Pulmonary Inflammation
}

\author{
Ken-ichiro INOUE $^{*, a}$ and Hirohisa TAKANO ${ }^{b}$ \\ ${ }^{a}$ Department of Public Health and Molecular Toxicology, School of Pharmacy, Kitasato University, 5-9-1 \\ Shirokane, Minato-ku, Tokyo 108-8641, Japan, and ${ }^{b}$ Environmental Health Sciences Division, \\ National Institute for Environmental Studies, 16-2 Onogawa, Tsukuba 305-8506, Japan
}

(Received September 8, 2010)

\begin{abstract}
Although the adverse health effects of diesel exhaust particles (DEP) have been proposed and are being clarified, their facilitating effects on preexisting pathological conditions (pathological conditions) have not been fully identified. On the other hand, there exist hypersensitive subjects against particulate matters. In this review, we provide insights into the immunotoxicity of DEP as an aggravating factor in hypersusceptible subjects, especially those with allergic pulmonary diseases using our in vivo experimental model. In brief, we examined the effects of DEP on allergic asthma in vivo, and showed that repetitive pulmonary exposure to DEP has promoting effects on allergic airway inflammation, including adjuvanticity on Th2-milieu. Further, we propose a causal machinery regarding the adverse impacts, i.e., via inappropriate activation of antigen-presenting cells such as dendritic cells.
\end{abstract}

Key words_ _ diesel exhaust particle; allergic pulmonary inflammation; antigen-presenting cell; dendritic cell; Th response

\section{OVERVIEW}

Motor vehicle emissions are a major source of airborne pollutants. ${ }^{1)}$ The combustion of fossil fuels produces a number of unhealthy substances, such as carbon monoxide, nitrogen oxides, benzene, sulfur dioxides, and particulate matters (PM). The largest single source of airborne PM from vehicles is derived from diesel exhaust. Advances in technology have resulted in diesel engines that produce less nitrogen oxide and particulate mass. However, diesel engines continue to emit higher emissions of gaseous substances and up to 100 times more particles compared with gasoline engines. In addition, with the high cost of fuel in many countries, use of diesel engines has increased due to their superior energy efficacy and endurance. Diesel fuel combustion results in the production of diesel exhaust particles (DEP), as well as gaseous compounds. DEP consist of an elemental carbon core with a large surface area to which hundreds of chemicals and metals are attached. The majority of DEP are classified as fine $(2.5-0.1 \mu \mathrm{m})$ or nano $(<0.1 \mu \mathrm{m})$ particles. It is accepted that DEP possess various health toxicity from mutagenesis to proinflammation. In this review, we provide insights

*e-mail: inouek@pharm.kitasato-u.ac.jp

This Review is based on the content of Symposia 33 (S33) of the 130th Annual Meeting of the Pharmaceutical Society of Japan. into the immunotoxicity of DEP as an aggravating factor in hypersusceptible subjects, in particular, those with allergic pulmonary diseases using our in vivo experimental model.

\section{Observational Studies on Adverse Health Effects of Diesel Exhaust Particles}

Previous epidemiological studies have indicated that exposure to ambient PM is linked to increases in mortality and morbidity related to cardiopulmonary diseases. ${ }^{2,3)}$ Reportedly, increased rates of myocardial infarction and hospitalization for cardiac events have been associated with higher air pollution concentrations. ${ }^{4-6)}$ In addition, numerous studies have shown associations between increased symptoms of cough, bronchitis, asthma, and chronic obstructive pulmonary disease and increased air pollutant levels. ${ }^{7-9)}$ Further, a study has shown that PM with a diameter less than $2.5 \mu \mathrm{m}$ (PM 2.5) is more closely associated with both acute and chronic respiratory effects including bronchial asthma and subsequent mortality than PM with a diameter less than $10 \mu \mathrm{m}$ (PM10). ${ }^{10)}$ On the other hand, some studies implicated the association between development of several types of cancer (lung, bladder, leukemia) and degree of air pollution including diesel exhaust. ${ }^{11-14)}$

\section{DEP as Immune Disruptors}

In general, experimentally, DEP are implicated to 
act as immune disruptors. For instances, DEP and/or their components enhance collagen-induced arthritis in mice, which is concomitant with amplified production of anti-collagen antibodies and secretion of interleukin (IL) -2 and interferon (IFN) $-\gamma^{15)}$ and induce/ elevate lupus-related specific autoantibodies in mice. ${ }^{16)}$ In addition, the previous studies on intranasal administration have reported that DEP with antigen demonstrate adjuvant activity for IgE production in mice by passive cutaneous anaphylaxis assay ${ }^{17)}$ and that those without antigen induce nasal nonspecific IgE response in humans. ${ }^{18,19)}$ These previous reports strongly suggest that DEP can disrupt immune system maybe toward inappropriate stimulation/activation of polyclonal immunoglobulin production (Fig. 1).

\section{Adjuvant Effects of DEP on Allergic Asthma}

Also, some data imply that PM is a risk factor for the development/exacerbation of allergic diseases' phenotype including bronchial asthma, allergic rhinitis, and atopic dermatitis. ${ }^{20-22)}$ In particular, during PM pollution episodes, asthmatic subjects reportedly demonstrate increased respiratory symptoms, bron- choconstriction, medication use, bronchial hyperreactivity, and emergency care visits. ${ }^{23,24)}$ Compatible with the above mentioned epidemiological investigation, we and others have experimentally demonstrated that exposure to DEP, representative constituents in PM2.5, exacerbate experimental asthma. ${ }^{25-29)}$ It has also been shown that airway exposure to DEP enhanced lung expression of Th cytokines (IL-4, IL-5, and/or IFN- $\gamma$ ) in the presence of antigen ${ }^{26,29)}$, indicating that DEP facilitates antigen-related airway inflammation, at least partly, through the enhanced Th response in the lung. Furthermore, our consecutive research has shown that repetitive pulmonary exposure to DEP in vivo, if combined with allergen, amplifies ex vivo allergen-specific Th2 response in the lung compared to that to allergen alone, characterized by high levels of IL-4 and IL-5, suggesting that in asthmatic subjects, DEP promote Th2-prone milieu in the lung, which additively/synergistically augment asthma pathophysiology in vivo. ${ }^{30)}$ As well, we have demonstrated that in vivo DEP exposure amplified extrathoracic CD4 polarization in asthmatic subjects (Fig. 1). . $^{31}$

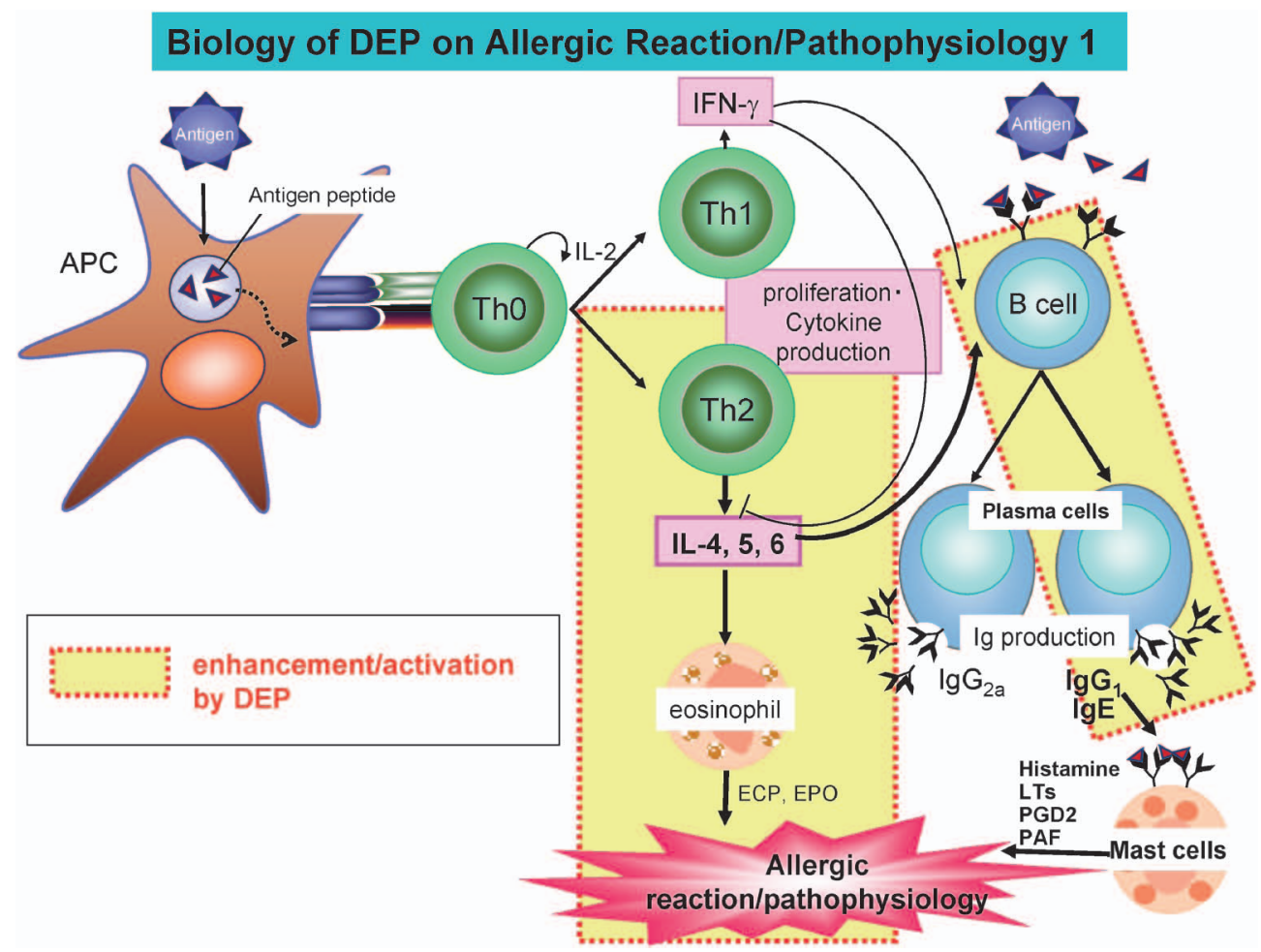

Fig. 1. Schematic View Relating DEP Biology on Allergic Reaction/Pathophysiology in the Context of Helper T (Th) 2-promoting Effect

DEP significantly enhance/activate Th2 response and accompany immunoglobulin production and eosinophilic inflammation (in the yellow area). 


\section{DEP on DC-T Cell Axis}

The role of antigen-presenting cells (APC), including dendritic cells, macrophages, and $\mathrm{B}$ cells, in the pathogenesis of allergic diseases has been relatively well defined. When antigens enter the airways, APC in the airways capture antigens and migrate to secondary lymphoid tissues such as draining lymph nodes. ${ }^{32}$ ) There, antigen-specific $\mathrm{T}$ cells differentiate into Th effector cells or regulatory $\mathrm{T}$ cells via an interaction with APC. ${ }^{33)}$ Indeed, pathological activation of APC reportedly enhances antigen-related airway inflammation in vivo. ${ }^{34,35)}$ Among APC, dendritic cells (DC) are recognized to be professional cell populations having potent antigen-presenting properties. ${ }^{32,33,36,37)}$ Several studies have identified a critical role for DC in antigen-related airway inflammation. ${ }^{38,39)}$ Indeed, in vitro data demonstrated that DEP exposure induces DC maturation ${ }^{40,41)}$ via epithelial cell-derived mediators ${ }^{42,43)}$ and that DEP-exposed DC induce a Th2 polarization..$^{40,44,45)}$

On the other hand, proallergic effects of DEP on T lymphocytes primed with in vivo antigen challenge remain obscure, although previous in vivo studies have demonstrated that DEP amplify the lung expres- sion of Th cytokines. ${ }^{26,29,46)}$ Indeed, it has been previously reported that one of components of DEP, pyrene, induces a Th milieu in both human and murine $\mathrm{T}$ cells in vitro. ${ }^{47)}$

In our previous study, the numbers of cells expressing MHC class II and/or co-stimulatory molecules (CD80 and CD86) in the lung were greater in the DEP + OVA group than in the other groups. ${ }^{41)}$ Furthermore, the numbers of DC, macrophages, and $\mathrm{B}$ cells bearing MHC class II in the lung were also increased by the administration of DEP to antigen-sensitized mice. It can be proposed that the enhanced expression of these APC-related molecules and increased pulmonary numbers of APC in the presence of antigen induced by DEP can, at least in part, play a role in the aggravating effects of DEP on the allergic response in the airway as reported previously. ${ }^{28,29)}$ Otherwise, the current data may lead to the scenario that DEP can synergistically increase the number of APC recruited into the lung in asthmatic mice, and in turn, can amplify functional activation of DC, which confer synergism for the enhancement of asthma pathophysiology.

Our previous study showed that DEP enhanced the response/pathway as demonstrated by the allogeneic

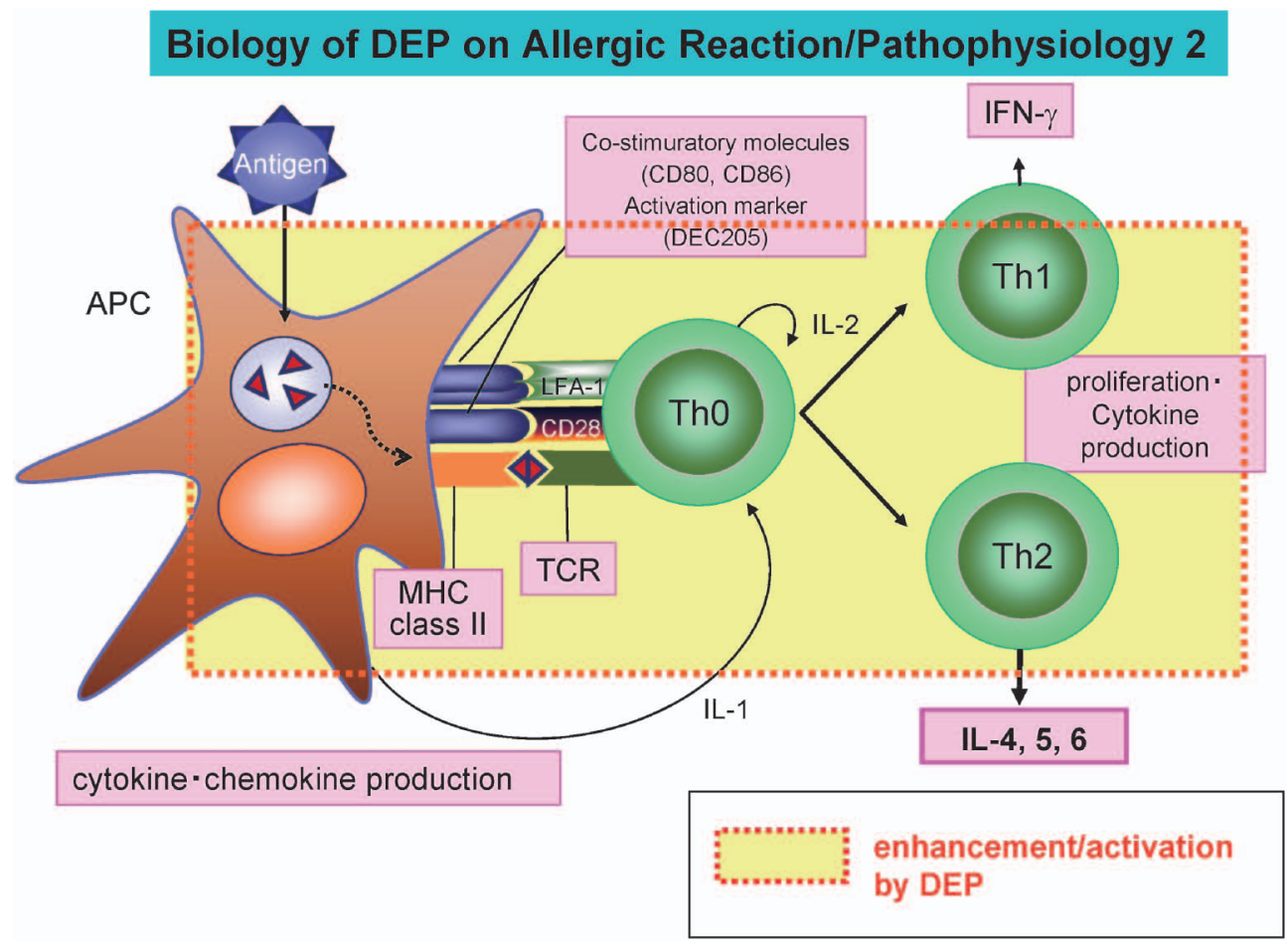

Fig. 2. Schematic View Relating DEP Biology on Allergic Reaction/Pathophysiology in the Context of Antigen-presenting Cell-activating Effect

DEP significantly enhance/activate antigen-presenting cell maturation/ and subsequent $\mathrm{T}$ cell proliferation toward Th2 milieu (in the yellow area). 
mixed lymphocyte reaction (MLR) and in particular, antigen-specific syngeneic lymphocyte reaction. ${ }^{41)}$ Also, we previously demonstrated that pulmonary exposure to DEP and their components amplified lung expressions of Th cytokines in vivo. ${ }^{28,29)}$ Also, in our recent study, when splenic mononuclear cells from the DEP + OVA group were stimulated with OVA, we found that they produced a greater amount of Th cytokines than those from the other groups. ${ }^{41)}$ Accordingly, the ex vivo results suggest that the enhancing effects of DEP on allergic asthma can be explained, at least in part, by skewing $\mathrm{T}$ cells toward a Th phenotype, especially during antigen priming. Furthermore, our in vitro and in vivo studies suggest that this Th-skewed susceptibility found in DEP plus OVA-primed lymphocytes could be mediated, at least in part, through amplified APC (DC) activity (Fig. 2).

\section{CONCLUSIVE REMARK}

Taking these in vivo, in vitro, and ex vivo studies from our laboratory as well as those from other ones into consideration, DEP is likely to serve as stimulator/activator/enhancer of immune response related to allergy, in which various disrupting steps exist.

\section{REFERENCES}

1) Riedl M., Diaz-Sanchez D., J. Allergy Clin. Immunol., 115, 221-228 (2005).

2) Abbey D. E., Nishino N., McDonnell W. F., Burchette R. J., Knutsen S. F., Lawrence Beeson W., Yang J. X., Am. J. Respir. Crit. Care Med., 159, 373-382 (1999).

3) Cohen A. J., Pope C. A., 3rd, Environ. Health Perspect., 103, 219-224 (1995) .

4) D'Ippoliti D., Forastiere F., Ancona C., Agabiti N., Fusco D., Michelozzi P., Perucci C. A., Epidemiology, 14, 528-535 (2003).

5) Mann J. K., Tager I. B., Lurmann F., Segal M., Quesenberry C. P., Jr., Lugg M. M., Shan J., Van Den Eeden S. K., Environ. Health Perspect., 110, 1247-1252 (2002).

6) Peters A., von Klot S., Heier M., Trentinaglia I., Hormann A., Wichmann H. E., Lowel H., N. Engl. J. Med., 351, 1721-1730 (2004).

7) "Report on a WHO Working Group. Bonn, Health aspects of air pollution with particulate matter, ozone, and nitrogen dioxide," World Health Organization, 2003.
8) WHO Working Group, Systemic review of health aspects of air pollution, 2003.

9) “Air Quality Criteria for Particulate Matter," Environmental Protection Agency, Chapel Hill (NC), 2003.

10) Peters A., Wichmann H. E., Tuch T., Heinrich J., Heyder J., Am. J. Respir. Crit. Care Med., 155, 1376-1383 (1997).

11) Ho C. K., Peng C. Y., Yang C. Y., J. Toxicol. Environ. Health A, 73, 23-32 (2009).

12) Chang C. C., Tsai S. S., Chiu H. F., Wu T. N., Yang C. Y., J. Toxicol. Environ. Health $A$, 72, 651-657 (2009).

13) Neumeyer-Gromen A., Razum O., Kersten N., Seidler A., Zeeb H., Int. J. Cancer, 124, 1900-1906 (2009).

14) Weng H. H., Tsai S. S., Chiu H. F., Wu T. N., Yang C. Y., J. Toxicol. Environ. Health $A$, 72, 83-87 (2009).

15) Yoshino S., Sagai M., J. Pharmacol. Exp. Ther., 290, 524-529 (1999).

16) Kuroda Y., Ono N., Akaogi J., Nacionales D. C., Yamasaki Y., Barker T. T., Reeves W. H., Satoh M., Toxicology, 218, 186-196 (2006) .

17) Takafuji S., Suzuki S., Koizumi K., Tadokoro K., Miyamoto T., Ikemori R., Muranaka M., J. Allergy Clin. Immunol., 79, 639-645 (1987).

18) Diaz-Sanchez D., Dotson A. R., Takenaka H., Saxon A., J. Clin. Invest., 94, 1417-1425 (1994).

19) Diaz-Sanchez D., Tsien A., Casillas A., Dotson A. R., Saxon A., J. Allergy Clin. Immunol., 98, 114-123 (1996).

20) Ring J., Eberlein-Koenig B., Behrendt H., Ann. Allergy Asthma Immunol., 87, 2-6 (2001).

21) Lee Y. L., Shaw C. K., Su H. J., Lai J. S., Ko Y. C., Huang S. L., Sung F. C., Guo Y. L., Eur. Respir. J., 21, 964-970 (2003).

22) Heinrich J., Wichmann H. E., Curr. Opin. Allergy Clin. Immunol., 4, 341-348 (2004).

23) Boezen M., Schouten J., Rijcken B., Vonk J., Gerritsen J., van der Zee S., Hoek G., Brunekreef B., Postma D., Am. J. Respir. Crit. Care Med., 158, 1848-1854 (1998).

24) Schwartz J., Slater D., Larson T. V., Pierson W. E., Koenig J. Q., Am. Rev. Respir. Dis., 147, 826-831 (1993). 
25) Dong C. C., Yin X. J., Ma J. Y., Millecchia L., Wu Z. X., Barger M. W., Roberts J. R., Antonini J. M., Dey R. D., Ma J. K., Toxicol. Sci., 88, 202-212 (2005).

26) Matsumoto A., Hiramatsu K., Li Y., Azuma A., Kudoh S., Takizawa H., Sugawara I., Clin. Immunol., 121, 227-235 (2006).

27) Hao M., Comier S., Wang M., Lee J. J., Nel A., J. Allergy Clin. Immunol. 112, 905-914 (2003).

28) Takano H., Ichinose T., Miyabara Y., Yoshikawa T., Sagai M., Immunopharmacol. Immunotoxicol., 20, 329-336 (1998).

29) Takano H., Yoshikawa T., Ichinose T., Miyabara Y., Imaoka K., Sagai M., Am. J. Respir. Crit. Care Med. 156, 36-42 (1997).

30) Inoue K., Koike E., Yanagisawa R., Takano H., J. Clin. Biochem. Nutr., 43, 199-200 (2008)

31) Inoue K., Koike E., Yanagisawa R., Takano H., Immunopharmacol. Immunotoxicol., 31, 71-74 (2009).

32) Kuipers H., Lambrecht B. N., Curr. Opin. Immunol., 16, 702-708 (2004).

33) Matsubara S., Koya T., Takeda K., Joetham A., Miyahara N., Pine P., Masuda E. S., Swasey C. H., Gelfand E. W., Am. J. Respir. Cell. Mol. Biol., 34, 426-433 (2006).

34) Upham J. W., Respirology, 8, 140-148 (2003).

35） Kato T., Tada-Oikawa S., Takahashi K., Saito K., Wang L., Nishio A., Hakamada-Taguchi R., Kawanishi S., Kuribayashi K., Eur. J. Immunol., 36, 1199-1209 (2006).

36) Banchereau J., Steinman R. M., Nature, 392, 245-252 (1998).

37) Banchereau J., Briere F., Caux C., Davoust
J., Lebecque S., Liu Y. J., Pulendran B., Palucka K., Ann. Rev. Immunol., 18, 767-811 (2000).

38) Lambrecht B. N., Salomon B., Klatzmann D., Pauwels R. A., J. Immunol., 160, 4090-4097 (1998).

39) van Rijt L. S., Jung S., Kleinjan A., Vos N., Willart M., Duez C., Hoogsteden H. C., Lambrecht B. N., J. Exp. Med., 201, 981-991 (2005)

40) Porter M., Karp M., Killedar S., Bauer S. M., Guo J., Williams D., Breysse P., Georas S. N., Williams M. A., Am. J. Respir. Cell. Mol. Biol., 37, 706-719 (2007).

41) Inoue K., Koike E., Takano H., Yanagisawa R., Ichinose T., Yoshikawa T., Exp. Biol. Med. (Maywood), 234, 200-209 (2009).

42) Bleck B., Tse D. B., Jaspers I., Curotto de Lafaille M. A., Reibman J., J. Immunol., 176 , 7431-7437 (2006).

43) Bleck B., Tse D. B., Curotto de Lafaille M. A., Zhang F., Reibman J., J. Clin. Immunol. 28, 147-156 (2008).

44) Chan R. C., Wang M., Li N., Yanagawa Y., Onoe K., Lee J. J., Nel A. E., J. Allergy Clin. Immunol., 118, 455-465 (2006).

45) Ohtani T., Nakagawa S., Kurosawa M., Mizuashi M., Ozawa M., Aiba S., J. Immunol., 174, 2412-2419 (2005).

46) Yanagisawa R., Takano H., Inoue K. I., Ichinose T., Sadakane K., Yoshino S., Yamaki K., Yoshikawa T., Hayakawa K., Clin. Exp. Allergy, 36, 386-395 (2006).

47) Bommel H., Li-Weber M., Serfling E., Duschl A., J. Allergy Clin. Immunol., 105, 796-802 (2000) 